Original Research Article

\title{
A comparative study of atorvastatin and rosuvastatin in dyslipidemia
}

\author{
Rudip Thapa $^{1 *}$, Prakash Rai ${ }^{1}$, Laxmi Mahara ${ }^{2}$, Sudarsana Chetty ${ }^{3}$
}

${ }^{1}$ Department of Clinical

Pharmacology, Nepal Medical

College, Atterkhel, Kathmandu, Nepal

${ }^{2}$ International Friendship

Children's Hospital,

Maharajgunj, Kathmandu, Nepal

${ }^{3}$ Department of Pharmacology,

College of Medical Science,

Bharatpur, Nepal

Received: 05 September 2017

Accepted: 03 October 2017

*Correspondence to:

Rudip Thapa,

Email: thaparudip88@

gmail.com

Copyright: (C) the author(s), publisher and licensee Medip Academy. This is an openaccess article distributed under the terms of the Creative Commons Attribution NonCommercial License, which permits unrestricted noncommercial use, distribution, and reproduction in any medium, provided the original work is properly cited.

\begin{abstract}
Background: To compare the drugs: Atorvastatin (10mg) and Rosuvastatin $(5 \mathrm{mg})$ in patients with Dyslipidemia.

Methods: This open-label, randomized, parallel group, comparative, prospective study of six months duration included 100 patients. The age group of patients varied from 30 to 69 years with dyslipidemia. Patients were divided in to 2 groups. 50 patients in group-1 received Atorvastatin $10 \mathrm{mg}$ once daily and 50 patients in group-2 received Rosuvastatin $5 \mathrm{mg}$ once daily. The level of TC, TG, LDL, VLDL and HDL were assessed at baseline and at the end of 3 months and 6 months.

Results: At 3 months, LDL was reduced significantly more with $5 \mathrm{mg}$ Rosuvastatin than with Atorvastatin $10 \mathrm{mg}$ [43.68\% vs. 40.74\% (P 0.0049)]. At 6 months, Rosuvastatin 5mg reduced LDL significantly more than Atorvastatin $10 \mathrm{mg}$ [48.69\% vs. 43.85\% (P 0.00)]. TC, HDL, TG and VLDL were more favourably modified by Rosuvastatin at 6 months $(\mathrm{P}<0.005)$. Reduction of total cholesterol levels in Rosuvastatin group was not statistically significant when compared with Atorvastatin group (P 0.103).

Conclusions: Rosuvastatin 5mg was more efficacious than Atorvastatin 10mg for the improvement of lipid profile during the period of 6 months follow-up drug therapy in patients with dyslipidemia.
\end{abstract}

Keywords: Atorvastatin, Dyslipidemia, Rosuvastatin

\section{INTRODUCTION}

Worldwide, hypercholesterolemia cause about $56 \%$ of ischemic heart disease and $18 \%$ of strokes, resulting to 4.4 million deaths annually. Hyperlipidemia and the rates of hypercholesterolemia (total cholesterol $\geq 201.1 \mathrm{mg} / \mathrm{dl}$ ) increased from $18 \%$ to $31 \%$ in adults aged $35-59 .{ }^{1}$ Studies have shown that the risk of ischemic heart disease in individuals with hypercholesterolemia is about thrice as great as in those with normal plasma cholesterol level indicating that reduction in plasma cholesterol does reduce the risk of myocardial infraction. ${ }^{2}$
There is increasing evidence that Hyperlipidemia is a major cause of atherosclerosis and atherosclerosisassociated conditions, such as coronary heart disease (CHD), ischemic cerebrovascular disease and peripheral vascular disease and reduction of TC and LDL-C below $442.86 \mathrm{mg} / \mathrm{dl}$ and $116 \mathrm{mg} / \mathrm{dl}$, respectively, lowers the incidence of CHD. The lifetime risk of developing CHD after 40 years of age is $49 \%$ in men and $32 \%$ in women. Even at 70 years of age, the risk is $35 \%$ for men and $24 \%$ for women. ${ }^{3}$ The lifetime risk of developing CVD at 50 years of age is estimated to be 1 in 2 for men and 2 in 5 for women in USA only. ${ }^{4}$ Numerous epidemiologic investigations have suggested that age, sex, elevated LDL- 
C level, low HDL-C level, DM, alcoholism and smoking are key risk factors for CHD. ${ }^{5,6}$ There is growing evidence that Statins, beyond their LDL cholesterol-lowering effects, possess so-called pleiotropic effects that could be have beneficial effects for patients with cardiovascular disease. ${ }^{7}$ Several observational studies suggest a large reduction in mortality in patients with ACS who were treated with Statins that were started prior to hospital discharge. ${ }^{8}$ In contrast, a recent meta-analysis concluded that initiation of Statin therapy within 14 days following onset of ACS does not reduce death, MI, or stroke as evaluated at 4-month follow-up. ${ }^{9}$ Additional studies evaluated the efficacy of an intensive Statin therapy in ACS patients. The PROVE-IT (Pravastatin or Atorvastatin Evaluation and Infection Therapy) trial enrolled 4162 patients with a recent diagnosis of ACS (STEMI in onethird of the total) and demonstrated that an intensive (Atorvastatin $80 \mathrm{mg}$ daily, target LDL-C $<70 \mathrm{mg} / \mathrm{dl}$ ) versus a moderate (Pravastatin 40mg daily, target LDL-C $<100 \mathrm{mg} / \mathrm{dl}$ ) lipid-lowering strategy is more effective in reducing the incidence of death or major cardiovascular events. $^{10}$

Plasma lipids consist of cholesterol (14\%), triacylglycerols (16\%), phospholipids (30\%), and cholesteryl esters (36\%) and a much smaller fraction of unesterified long-chain fatty acids (free fatty acids) (4\%). The free fatty acids (FFA), is metabolically the most active of the plasma lipids. ${ }^{11}$

Study on hypolipidemic drugs on lipid profile has been carried out many times in India, China, Japan, and UK, USA and other countries, which shows the relationship between hypolipidemic drugs in maintaining lipid profile. In Nepal this may be the very first study of its kind which will help to provide related data about the effect of Statins on lipid profile in Nepalese population. Due to more sedentary lifestyle at old age and use of alcohol and smoking, Nepalese population are being more prone to cardiovascular diseases like Hypertension, CAD etc. Mainly low level of HDL-C and elevated TG and LDL-C are clearly associated with excess risk of CVD and this association holds across racial and ethnic divisions.

\section{METHODS}

It is a hospital based open label comparative study of 100 patients above 15 years of age with case of Dyslipidemia. The study was conducted in out patient and admitted patient after obtaining written consent in CMSTH (College of Medical Sciences- Teaching Hospital), Bharatpur, Chitwan, Nepal during December 2010 to June 2011 with an aim to find out the effect of two Statins I.e. Atorvastatin and Rosuvastatin on lipid profile. Randomly selected 100 cases of dyslipidemia meeting the inclusion criteria (Modified NCEP ATP III criteria, Table 1) in to 2 groups. ${ }^{12}$ Each group contains 50 patients and given Atorvastatin $10 \mathrm{mg}$ and Rosuvastatin $5 \mathrm{mg}$. Each case was followed up after 3 months and 6 months. After taking history and clinical examination, Fasting Serum TC, TG, HDL, LDL and VLDL level were measured. Patients were excluded if they were pregnant or had malignancy, having active arterial disease such as unstable angina, myocardial infarction, cerebrovascular accident, coronary artery bypass surgery, or angioplasty within 2 months prior to study. Liver disease, Malnutrition, Hyperthyroidism, Infection with hepatitis $\mathrm{C}$ virus (HCV), and Patients taking oral contraceptives are also excluded.

Table 1: The ATP III guideline recommends total cholesterol level. ${ }^{12}$

\begin{tabular}{|ll|}
\hline Unit $\mathrm{mg} / \mathrm{dl}$ & \\
\hline$<200 \mathrm{mg} / \mathrm{dl}$ & Desirable \\
\hline $200-239 \mathrm{mg} / \mathrm{dl}$ & Borderline high \\
\hline$\geq 240 \mathrm{mg} / \mathrm{dl}$ & High \\
\hline
\end{tabular}

Data was recorded on predesigned proforma. Results were expressed as mean, standard deviation and LSM \% change. Different statistical test of significance (student's ' $t$ ' test and chi square test) were applied to find the $\mathrm{p}$ value. $\mathrm{P}$ value less than 0.05 was considered statistically significant.

\section{RESULTS}

Total of 100 patients were involved in the study, mean age was $49.12 \pm 8.83$ years out of which 54 were female and 46 males. Among 50 patients receiving Atorvastatin, 30 were male and 20 were female and the mean age was $47.64 \pm 10.39$ years. The mean age of group receiving Rosuvastatin was $50 \pm 8.26$ years of which 24 were male and 26 were female. According to ethnicity $30 \%$ were Brahmins, 27\% were Chhetry and Thakuri, 21\% Mongols like Gurungs, Rai, Tamang, Pun, Lama, Rana and 22\% were other which include Chaudhary, Maheto, Yadav, Pariyar. The demography shows that $89 \%$ of the patients were involved in either smoking or in consumption of alcohols or having past history of either of them. The age of the patients in study group ranged from 30 years to 70 years with a mean age of 49.12 years.

\section{Table 2: Patient demographics and baseline characteristics (randomized population).}

\begin{tabular}{|lll|}
\hline $\begin{array}{l}\text { Lipid } \\
\text { prolife }\end{array}$ & Atorvastatin 10mg & Rosuvastatin 5mg \\
\hline TC & $265.39 \pm 15.57$ & Mean \pm SD \\
\hline TG & $220.51 \pm 40.77$ & $227.03 \pm 17.39$ \\
\hline HDL & $38.14 \pm 7.43$ & $40.15 \pm 6.18$ \\
\hline LDL & $183.12 \pm 13.72$ & $186.54 \pm 13.39$ \\
\hline VLDL & $44.1 \pm 8.20$ & $45.45 \pm 7.7$ \\
\hline
\end{tabular}

Number of male and female patients was 54 and 46 respectively. This indicated higher incidence of dyslipidemia in male patients. The maximum number of dyslipidemia patients was found in age group between 41$60(41 \%)$ of which 33 were male and 40 were female. Brahmins ethnicity patients had higher percentage $(30 \%)$ 
of dyslipidemia followed by Chhetry and Thakuri (27\%), Mongols (21\%) and others 22\% including Chaudhary, Maheto, Yadav, Pariyar. Total of $89 \%$ of subject intention to treat had past history of either alcohol or smoking or both.

The two groups were well matched at baseline and demographic details were obtained which is shown in tables below. Patient demographics and the mean baseline at initial stage of study (Table 2), at three months (Table
3) and six months (Table 4) were obtained with LSM change in percentage in lipid parameters.

Rosuvastatin 5mg increased HDL-C levels to a significantly greater extent than atorvastatin $10 \mathrm{mg}$ (mean change $6.4 \%$ and $3.1 \%, \mathrm{p}<0.001$ ), while similar reductions in $\mathrm{TC}$, TG, and non HDL-C levels were observed with both treatments.

Table 3: Change from baseline in lipoprotein and lipid levels after 3 months of treatment.

\begin{tabular}{|llllll|}
\hline Lipid profile & $\begin{array}{l}\text { Atorvastatin 10mg } \\
\text { Mean baseline level, } \\
\mathbf{m g} / \mathbf{d L} \pm \text { SD }\end{array}$ & $\begin{array}{l}\text { LSM percentage } \\
\text { change }\end{array}$ & $\begin{array}{l}\text { Rosuvastatin } \text { 5mg } \\
\text { Mean baseline } \\
\text { level, } \mathbf{m g} / \mathbf{d L} \pm \text { SD }\end{array}$ & $\begin{array}{l}\text { LSM percentage } \\
\text { change }\end{array}$ & P - value \\
\hline TC & $177.87 \pm 11.35$ & 32.9 & $185.64 \pm 13.9$ & 31.67 & 0.03 \\
\hline TG & $149.81 \pm 20.66$ & 31.12 & $181.66 \pm 26.75$ & 19.61 & 0.00 \\
\hline HDL & $39.75 \pm 7.41$ & 4.12 & $44.69 \pm 6.79$ & 10.19 & 0.001 \\
\hline LDL & $108.39 \pm 8.52$ & 40.74 & $104.74 \pm 10.34$ & 43.68 & 0.049 \\
\hline VLDL & $29.94 \pm 4.12$ & 31.16 & $36.31 \pm 5.35$ & 19.69 & 0.00 \\
\hline
\end{tabular}

Table 4: Change from baseline in lipoprotein and lipid levels after 6 months of treatment.

\begin{tabular}{|llllll|}
\hline Lipid profile & $\begin{array}{l}\text { Atorvastatin 10mg } \\
\text { Mean baseline level, } \\
\text { mg/dL } \mathbf{S D}\end{array}$ & $\begin{array}{l}\text { LSM percentage } \\
\text { change }\end{array}$ & $\begin{array}{l}\text { Rosuvastatin } \mathbf{5 m g} \\
\text { Mean baseline } \\
\text { level, } \mathbf{m g} / \mathbf{d L} \pm \text { SD }\end{array}$ & $\begin{array}{l}\text { LSM percentage } \\
\text { change }\end{array}$ & P - value \\
\hline TC & $172.54 \pm 11.21$ & 34.94 & $176.51 \pm 12.83$ & 35.01 & 0.103 \\
\hline TG & $140.62 \pm 19.48$ & 35.42 & $167.95 \pm 23.56$ & 25.56 & 0.00 \\
\hline HDL & $41.72 \pm 7.58$ & 8.71 & $47.47 \pm 6.75$ & 15.51 & 0.00 \\
\hline LDL & $102.69 \pm 8.2$ & 43.85 & $95.44 \pm 9.73$ & 48.69 & 0.00 \\
\hline VLDL & $28.12 \pm 3.89$ & 35.42 & $33.59 \pm 4.71$ & 25.6 & 0.00 \\
\hline
\end{tabular}

\section{DISCUSSION}

Data from two groups were analyzed for an efficacy comparison in the intention-to-treat population. Baseline values of all parameters were similar between the two groups. The mean Serum TC, TG, LDL-C and VLDL-C levels were significantly reduced on therapy. Simultaneously, the mean level of HDL-C was highly significantly increased after therapy with both Atorvastatin and Rosuvastatin. At 3 months duration of drug treatment, Atorvastatin $10 \mathrm{mg}$ reduced the level of TC by $32.9 \%$ which is similar with the findings of Kuryata et al, TG by $31.12 \%$, LDL-C $40.74 \%$ as reported by Zhonghu et al, and VLDL-C $31.16 \%$ respectively. ${ }^{13,14}$ The level of HDL-C was increased by $4.12 \%$ which is similar as reported by Zhonghu et al, and at 6 months duration Atorvastatin 10mg reduced the level of TC by $34.94 \%$, TG by $35.42 \%$, LDLC $43.85 \%$ and VLDL-C $35.42 \%$ respectively. ${ }^{14}$ The level of HDL-C was increased by $8.71 \%$ as reported by Save et al. ${ }^{15}$

At 3 months duration of drug treatment, Rosuvastatin $5 \mathrm{mg}$ reduced the level of TC by $31.67 \%$ and LDL-C $43.68 \%$ which is similar with the findings of Teramoto et al, and VLDL-C $31.16 \% .^{16}$ The level of HDL-C was increased by $10.19 \%$ which is similar as reported by Teramoto et al, and at 6 months of duration Rosuvastatin $5 \mathrm{mg}$ reduced the level of TC by $35.01 \%$, TG by $25.56 \%$, LDL-C $48.69 \%$ and VLDL-C $25.6 \%$ respectively. ${ }^{16}$ The level of HDL-C was increased by $15.5 \%$.

This study showed that Rosuvastatin $5 \mathrm{mg}$ has better efficacy in comparison to Atorvastatin $10 \mathrm{mg}$ for the treatment of Dyslipidemia. While comparing mean \% reduction, both groups of patients had significant reduction in lipids and lipoprotein levels during 6 months of drug treatment. Rosuvastatin enabled significantly more patients to achieve the National Cholesterol Education Program (NCEP) goals compared to Atorvastatin with LDL-C (74\% vs $48 \%)$, TC (100\% vs $98 \%)$, HDL (male $52.94 \%$ vs $48 \%$, female $50 \%$ vs $26 \%$ ). Number of patients to achieve the National Cholesterol Education Program (NCEP) goals for TG were found more in Atorvastatin group compared to Rosuvastatin (66\% vs $30 \%)$. As many clinical trail observations have demonstrated the superiority of Rosuvastatin over Atorvastatin in lowering 
level of LDL-C, TG, TC, VLDL-C and raising level of HDL-C, my study also has similar pattern of findings. At 6 months of drug treatment, Rosuvastatin $5 \mathrm{mg}$ produced a significantly greater reduction in TC, LDL-C, TG and VLDL-C in compared to Atorvastatin 10mg. Rosuvastatin $5 \mathrm{mg}$ also significantly raised HDL-C level than Atorvastatin $10 \mathrm{mg}$ in this study.

Schwartz et al, in the study of 383 cases of hypercholesterolemia and high risk of CHD patients at 3 months of drug treatment with Rosuvastatin $5 \mathrm{mg} /$ day and Atorvastatin $10 \mathrm{mg} /$ day found to decrease LDL-C by $40 \%$ and $35 \%$ respectively. ${ }^{17} \mathrm{TC}$, HDL-C, and VLDL-C were more favourably modified by Rosuvastatin at 6 months of drug treatment which is similar to the result with my study. Effects of the both agents on TG were similar as reported by my study.

Blasetto et al, report significant improvement in lipids and lipoprotein levels with the treatment of Rosuvastatin $5 \mathrm{mg}$ compared to that with Atorvastatin $10 \mathrm{mg}$ which is very similar to the result in my study. ${ }^{18}$ A similar comparative study done by Schneck et al, on 374 hypercholesterolemia patients without active arterial disease showed that Rosuvastatin was significantly effective in compared to Atorvastatin in maintaining lipid profile which is similar with the result of my study. ${ }^{19}$

Davidson et al, in the study of 516 North American population found that Rosuvastatin $5 \mathrm{mg}$ /day in compared to Atorvastatin $10 \mathrm{mg} /$ day were associated with greater in LDL-C, reduction and HDL-C increase which is similar with the result of my study. ${ }^{20}$ Reduction in the TC and TG did not match with result of my study of 3 months periods. The possible explanation for this conflicting result may be that, patients in my study did not have any dietary run-in before the drug therapy. The sample size also being small in my study may be the cause.

Kurabayashi et al, in the study with Japanese patients found that Rosuvastatin $5 \mathrm{mg} /$ day is a useful treatment option than Atorvastatin 10mg/day for high risk patients with hypercholesterolemia which is similar with the result of my study. ${ }^{21}$

Park et al, in the study with 351 Korean patients with metabolic syndrome and hypercholesterolemia found greater reduction in TC and LDL-C level by Rosuvastatin treatment as compared to Atorvastatin treatment which is similar with the result of my study. ${ }^{22}$

A 48 week randomized, parallel group, open label study done in 106 patients with primary hypercholesterolemia by Mazza et al, showed that Rosuvastatin was associated with significantly greater reduction in LDL-C, TC, and TG compared to Atorvastatin which resembles with the result of my study. ${ }^{23}$

A comparative study done by Otokozawa et al, also showed that maximum dose Rosuvastatin 40mg/day was significantly more effective than Atorvastatin $80 \mathrm{mg} /$ day in reducing LDL-C, TG and TC which supports the result of my study. ${ }^{24}$ Similar study done by Lloret et al, also showed that Rosuvastatin significantly decreases lipid and lipoproteins level compared with Atorvastatin is also supportive to the result of my study. ${ }^{25}$

Olsson et al, report Rosuvastatin $5 \mathrm{mg}$ /day was associated with significantly greater LDL reduction than Atorvastatin $10 \mathrm{mg} /$ day which is similar with the result of my study. ${ }^{26}$

\section{CONCLUSION}

The result of this study shows that at recommended dose, Rosuvastatin (5mg/day) was more efficacious than Atorvastatin (10mg/day), in terms of improving lipid profile in the period of 6-month follow-up. The greater efficacy of Rosuvastatin at recommended dose should help to enable more patients to achieve recommended treatment goals in clinical practice. In addition, improvements across the whole lipid profile may provide further reductions in the risk of CVD. With the goal of more improvements in lipid profile, further study will be needed to determine whether more stringent statin monotherapy or combination treatment is needed for better outcomes in patients with the Dyslipidemia.

Funding: No funding sources

Conflict of interest: None declared

Ethical approval: The study was approved by the Institutional Ethics Committee

\section{REFERENCES}

1. Zhang $\mathrm{XH}, \mathrm{Lu} \mathrm{ZL}$, Liu L. Coronary heart disease in China. Heart. 2008;94(9):1126-31.

2. Rang HP, Dale MM, Ritter JM, Flower RJ. Rang \& Dale's Pharmacology, $6^{\text {th }}$ Ed. Elsvier, Churchill Livingstone, Philadelphia; 2007.

3. Lloyd-Jones DM, Larson MG, Beiser A, Levy D. Lifetime risk of developing coronary heart disease. Lancet. 1999;353:89-92.

4. Lloyd-Jones DM, Leip EP, Larson MG, D’Agostino RB, Beiser A, Wilson PWF, et al. Prediction of lifetime risk for cardiovascular disease by risk factor burden at 50 years of age. Circulation. 2006;113:7918.

5. Grundy SM, D'Agostino S, Mosca L, Burke GL, Wilson PWF, Rader DJ, et al. Cardiovascular risk assessment based on U.S. cohort studies: findings from a national heart, lung, and blood institute workshop. Circulation. 2001;104:491.

6. Wilson PW, D'Agostino RB, Sullivan L, Parise H, Kannel WB. Overweight and obesity as determinants of cardiovascular risk: the Framingham experience. Arch Intern Med. 2002;162:1867-2.

7. Sposito AC, Chapman MJ. Statin therapy in acute coronary syndromes: mechanistic insight into clinical benefit. Arterioscler Thromb Vasc Biol. 2002;22:1524-34. 
8. Aronow HD, Topol EJ, Roe MT, Houghtaling PL, Wolski KE, Lincoff AM, et al. Effect of lipid-lowering therapy on early mortality after acute coronary syndromes: an observational study. Lancet. 2001;357:1063-8.

9. Cannon CP, Braunwald E, McCabe CH, Rader DJ, Rouleau JL, Belder R, et al. Intensive versus moderate lipid lowering with statins after acute coronary syndromes. N Engl J Med. 2004;350:1495-504.

10. Hulten E, Jackson JL, Douglas K, George S, Villines TC. The effect of early, intensive statin therapy on acute coronary syndrome: a meta-analysis of randomized controlled trials. Arch Intern Med. 2006;166:1814-21.

11. Robert KM, Daryl KG, Peter AM, Victor WR. Harper's Illustrated Biochemistry: Lipid Transport \& Storage. $26^{\text {th }}$ Ed. The McGraw-Hill Companies; 2003.

12. Third report of the National Cholesterol Education Program (NCEP) Expert Panel on detection, evaluation, and treatment of high blood cholesterol in Adults (Adult Treatment Panel III) final report. Circulation. 2002;106:3143-421.

13. Kuryata OV, Yegorova YV. The influence of lowdose atorvastatin on lipid levels and endothelial vascular function in patients with significant coronary artery stenosis. Kardiol Pol. 2006;64(1):44-8.

14. Gao RL. The efficacy and safety of rosuvastatin on treating patients with hypercholesterolemia in Chinese: a randomized, double-blind, multi-center clinical trial. Zhonghua xin xue guan bing za zhi. 2007 Mar;35(3):207-11.

15. Save V, Patil N, Moulik N, Rajadhyaksha G. Effect of atorvastatin on type 2 diabetic dyslipidemia. J Cardiovasc Pharmacol Ther. 2006;11(4):262-70.

16. Teramoto $\mathrm{T}$, Watkins $\mathrm{C}$. Review of efficacy of rosuvastatin 5mg. Int J Clin Pract. 2005;59(1):92-101.

17. Schwartz GG, Bolognese MA, Tremblay BP, Caplan R, Hutchinson H, Raza A, et al. Efficacy and safety of rosuvastatin and atorvastatin in patients with hypercholesterolemia and a high risk of coronary heart disease: a randomized, controlled trial. Am Heart J. 2004;148(1):4.

18. Blasetto JW, Stein EA, Brown WV, Chitra R, Raza A. Efficacy of rosuvastatin compared with other statins at selected starting doses in hypercholesterolemic patients and in special population groups. Am J Cardiol. 2003;91(5A):3-10.
19. Schneck DW, Knopp RH, Ballantyne CM, McPherson R, Chitra RR, Simonson SG. Comparative effects of Rosuvastatin and Atorvastatin across their dose range in patients with hypercholesterolemia and without active arterial disease. Am J Cardiol. 2003;91:33-41.

20. Davidson M, Ma P, Stein EA, Gotto AM Jr, Raza A, Chitra R, Hutchinson H. Comparison of effects on low-density lipoprotein cholesterol and high-density lipoprotein cholesterol with rosuvastatin versus atorvastatin in patients with type IIa or IIb hypercholesterolemia. Am J Cardiol. 2002;89(3):26875 .

21. Kurabayashi M, Yamazaki T. Superior benefit of aggressive lipid-lowering therapy for high- risk patients using statins. J Atheroscler Thromb. 2008;15(6):314-23.

22. Park JS, Kim YJ, Choi JY, Kim YN, Hong TJ, Kim DS, et al. Comparative study of low doses of rosuvastatin and atorvastatin on lipid and glycemic control in patients with metabolic syndrome and hypercholesterolemia. Korean $\mathrm{J}$ Intern Med. 2010;25(1):27-35.

23. Mazza F, Stefanutti C, Di Giacomo S, Vivenzio A, Fraone N, Mazzarella B, et al. Effects of low-dose atorvastatin and rosuvastatin on plasma lipid profiles: a long-term, randomized, open-label study in patients with primary hypercholesterolemia. Am J Cardiovasc Drugs. 2008;8(4):265-70.

24. Otokozawa S, Ai M, Asztalos BF, Nakajima K, Stein E, Jones PH, et al. Effects of maximal doses of atorvastatin versus rosuvastatin on small dense lowdensity lipoprotein cholesterol levels. Am J Cardiol. 2008;101(3):315-8.

25. Lloret R, Ycas J, Stein M, Haffner S. Comparison of rosuvastatin versus atorvastatin in HispanicAmericans with hypercholesterolemia (from the STARSHIP trial). Am J Cardiol. 2006;98(6):768-73.

26. Olsson AG, Istad H, Luurila O, Ose L, Stender S, Tuomilehto $\mathrm{J}$, et al. Effects of rosuvastatin and atorvastatin compared over 52 weeks of treatment in patients with hypercholesterolemia. Am Heart J. 2002;144(6):1044-51.

Cite this article as: Thapa $\mathrm{R}$, Rai $\mathrm{P}$, Mahara L, Chetty S. A comparative study of atorvastatin and rosuvastatin in dyslipidemia. Int $\mathrm{J}$ Basic Clin Pharmacol 2017;6:2551-5. 